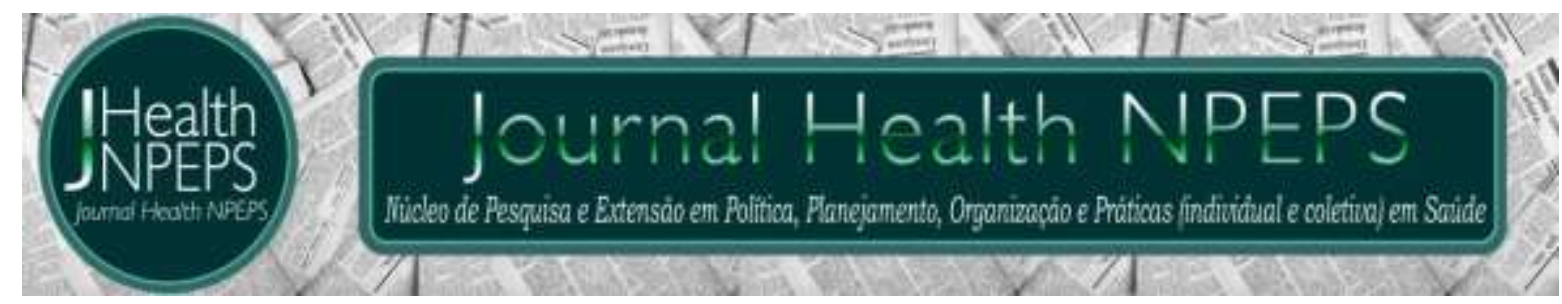

http://dx.doi.org/10.30681/252610103297

ARTIGO ORIGINAL

\title{
Conhecimentos da equipe de enfermagem no cuidado intensivo a pacientes em hemodiálise
}

\author{
Knowledge of the nursing team in the intensive care to patients on \\ hemodialysis
}

\section{Conocimiento del equipo de enfermería en los cuidados intensivos para pacientes en hemodiálisis}

\section{Paulo Eduardo Bastos Barbosa Silva ${ }^{1}$, Magda de Mattos ${ }^{2}$}

\section{RESUMO}

Objetivo: descrever os conhecimentos da equipe de enfermagem acerca dos cuidados intensivos a pacientes em tratamento hemodialítico. Método: estudo descritivo e com abordagem qualitativa, realizada por meio de entrevista semiestruturada com 11 profissionais da equipe de enfermagem de uma unidade de terapia intensiva geral, em município do estado de Mato Grosso, no ano de 2016. De acordo com a análise de conteúdo de Bardin, emergiram três categorias: "aprendi com os colegas", "a hemodiálise é coisa séria" e "o conhecimento é para todos". Resultados: os profissionais de enfermagem reconhecem que os conhecimentos acerca dos cuidados aos pacientes em hemodiálise são limitados e foram adquiridos por intermédio de outros colegas. Conclusão: a equipe de enfermagem necessita de medidas educativas, como a educação permanente, para que possam organizar e prestar o cuidado aos pacientes em tratamento hemodialítico fundamentados em conhecimentos técnicos e científicos.

Descritores: Diálise Renal; Cuidados de Enfermagem; Segurança do Paciente; Educação Permanente.

\section{ABSTRACT}

Objective: to describe the knowledge of the nursing team about the intensive care to patients on hemodialysis. Method: descriptive study with a qualitative approach, carried out by means of semi-structured interviews with 11 professionals from the nursing team in a general Intensive Care Unit, in a municipality of the state of Mato Grosso, in the year 2016. According to the content analysis of Bardin, three categories emerged: "I have learned with colleagues", "Hemodialysis is a serious thing" and "knowledge is for everyone". Results: the nursing professionals recognize that knowledge about the care to patients on hemodialysis is limited and acquired through other colleagues. Conclusion: the nursing team needs educational measures, such as permanent education, so that they can organize and provide care to patients on hemodialysis based on technical and scientific knowledge.

${ }^{1}$ Enfermeiro. Especialista em Saúde do Adulto e Idoso. Docente dos cursos de Enfermagem e de Fisioterapia da Universidade de Cuiabá. Rondonópolis, MT, Brasil. E-mail: pauloeduardobastos@gmail.com ORCID ID: https://orcid.org/0000-0002-5101-1477 Autor principal - Endereço para correspondência: Rua Otávio Pitaluga, no 505, Residencial Greenville - Apto. 03, Bairro Vila Aurora 1- Rondonópolis/MT.

${ }^{2}$ Enfermeira. Doutora em Educação. Docente Adjunta da Universidade Federal de Rondonópolis (UFR). Rondonópolis, MT, Brasil. E-mail: magda_roo@hotmail.com ORCID ID: https://orcid.org/0000-0001-8330$\underline{1084}$ 
Descriptors: Renal Dialysis; Nursing Care; Patient Safety; Continuing Education.

\section{RESUMEN}

Objetivo: describir el conocimiento del equipo de enfermería acerca de los cuidados intensivos para pacientes en hemodiálisis. Método: estudio descriptivo y con abordaje cualitativo, realizado por medio de entrevistas semiestructuradas con 11 profesionales del equipo de enfermería en una unidad de cuidados intensivos generales, en el municipio del estado de Mato Grosso, en el año 2016. De acuerdo con el análisis del contenido de Bardin, emergieron tres categorías: "He aprendido con colegas", "La hemodiálisis es una cosa seria" y que "El conocimiento es para todos". Resultados: los profesionales de enfermería reconocen que los conocimientos acerca de los cuidados a los pacientes en hemodiálisis son limitados y fueron adquiridos por otros colegas. Conclusión: el personal de enfermería necesita de medidas educativas, como la educación permanente, a fin de que puedan organizar y prestar atención a los pacientes en hemodiálisis basado en conocimientos técnicos y científicos.

Descriptores: Diálisis Renal; Cuidados de Enfermería; Seguridad del Paciente; Educación Continua.

\section{INTRODUÇÃO}

A prática do cuidar em enfermagem na Unidade de Terapia Intensiva (UTI) exige dos profissionais, conhecimentos teóricos e práticos consistentes para o atendimento aos pacientes em condições críticas, proporcionando uma assistência altamente especializada ${ }^{1}$.

São inúmeras as alterações orgânicas apresentadas pelos pacientes internados em UTI, e dentre essas, têm-se o comprometimento da função renal, seja por eventos nefrotóxicos, isquêmicos, infecciosos ou obstrutivos, logo trazendo prejuízos aos processos fisiológicos de filtração, reabsorção e excreção ${ }^{2,3}$, dando origem a Lesão Renal Aguda (LRA) ou a Doença Renal Crônica (DRC).

A LRA se caracteriza por uma queda abrupta do ritmo de filtração glomerular, acompanhada pela retenção de produtos nitrogenados e distúrbios hidroeletrolíticos. Já, a DRC é assintomática, gradual e silenciosa, ocasionando deterioração progressiva em meados de um longo período de tempo, cujos sinais e sintomas se manifestam de forma mais evidente na fase avançada da doença, em que 0 indivíduo apresente uma taxa de filtração glomerular $\left(\right.$ TFG) $<60 \mathrm{ml} / \mathrm{min} / 1,73^{3}$ em três meses consecutivos ${ }^{3,4}$.

$\mathrm{Na}$ falência renal aguda ou crônica torna-se necessária a diálise, procedimento que visa a remoção das substâncias tóxicas e o equilíbrio hidroeletrolítico. Para isso, há duas modalidades, a hemodiálise e diálise peritoneal ${ }^{2,3}$.

A escolha e definição final da modalidade segue critérios médicos e condições hemodinâmicas dos pacientes, embora que a opção mais utilizada é a hemodiálise. Ela se caracteriza como uma tecnologia dura, mediada pela conexão do paciente à um rim artificial. 0 
acesso venoso para o procedimento hemodialítico é realizado por meio de fístula arteriovenosa (FAV) ou pela inserção de um cateter temporário duplo lúmen (CTDL) em vaso de grosso calibre $3,5,6$.

Dentre os fatores que contribuem para a eficiência e eficácia desse tratamento na UTI, encontra-se o nível de capacitação e treinamento da equipe, que muitas vezes é negligenciado ou desconsiderado, ao apoiarem somente no tempo de atuação na área como sendo sinônimo de assistência qualificada e segura. Neste contexto, questiona-se quais são os conhecimentos da equipe de enfermagem junto a pacientes submetidos à hemodiálise? Para isso, o objetivo do estudo foi descrever os conhecimentos da equipe de enfermagem acerca dos cuidados intensivos a pacientes em tratamento hemodialítico.

\section{MÉTODO}

Trata-se de pesquisa descritiva e com abordagem qualitativa, realizada em uma UTI geral, de hospital filantrópico referência na região sul do estado de Mato Grosso, com 10 leitos. A escolha da instituição deu-se em razão de ser um dos campos de atuação prática do Programa de Residência Multiprofissional em Saúde do Adulto e Idoso da Universidade Federal de Mato Grosso
(UFMT), no qual os pesquisadores estão inseridos.

A seleção dos participantes ocorreu de forma intencional, por meio de convite para participação no estudo. Como critérios de inclusão definiram-se os seguintes: ser enfermeiro ou técnico de enfermagem lotado e atuando na UTI, atuante na unidade no mínimo há três meses; ter idade igual ou superior a 18 anos e que tivesse disponibilidade e aceitasse participar da pesquisa por meio da assinatura do Termo de Consentimento Livre e Esclarecido (TCLE). Foram excluídos os profissionais que se encontravam afastados em virtude de licença médica ou férias.

A coleta de dados ocorreu no período de setembro a dezembro de 2016, no próprio hospital com data e horário previamente agendado e para o qual se utilizou a entrevista semiestruturada com perguntas abertas e fechada, as quais foram gravadas e transcritas na íntegra. Com intuito de preservar 0 anonimato os participantes foram denominados de ENF para apresentação das enfermeiras e TE para técnicos de enfermagem, enumerados sequencialmente conforme a realização das entrevistas.

Para a análise dos dados foi adotada a análise de conteúdo ${ }^{7}$, compreendendo três etapas: a préanálise, a exploração do material e por fim, a inferência e interpretação 
dos resultados. Emergiram as seguintes categorias: "aprendi com os colegas", "a hemodiálise é coisa séria" e "o conhecimento é para todos".

A pesquisa obedeceu aos preceitos éticos regulamentados pela Resolução 466/2012 ${ }^{8}$, recebendo aprovação do Comitê de Ética em Pesquisa com Seres Humanos da Universidade Federal de Mato Grosso (CEP/UFMT), com CAAE $n^{\circ}$ 59428216.0.0000.5587 e parecer $n^{\circ}$ 1.719.453.

\section{RESULTADOS E DISCUSSÃO}

Participaram do estudo 11 membros da equipe de enfermagem, três do gênero masculino e oito femininos. Quanto à ocupação profissional, três constituíam-se de enfermeiras, com tempo de atuação inferior a cinco anos e oito técnicos de enfermagem, com experiência profissional na UTI entre três a dezoito anos.

\section{Aprendi com os colegas}

Segundo os relatos da equipe de enfermagem, o conhecimento sobre a assistência no tratamento hemodialítico, ocorreu por interesse pessoal e/ou pela necessidade do próprio serviço de saúde, porém, verificou-se carência de conhecimentos técnicos e científicos para realização desse cuidado.
A gente vai pegando o conhecimento através dos colegas, os que querem ajudar, $e$ se tivermos o interesse em aprender. A gente vai se aproximando da hemodiálise $e$ descobrindo os truques $e$ as manhas da hemodiálise, mas por parte do hospital eu, pelo menos, não fiz nenhum treinamento. (TE6)

Aprendi mesmo no dia a dia, com instruções da enfermeira e uma amiga técnica de enfermagem que já tinha certa experiência em hemodiálise. (TE8)

Este aprendizado [hemodiálise] eu peguei dos meus colegas que são os técnicos de enfermagem. Os técnicos do meu plantão que me ensinaram a fazer a hemodiálise, que me orientaram [...]. (ENF2)

[...] foi muito difícil, pois no início o hospital obrigava a gente a aprender sem nenhuma base, tinha por que tinha que se virar e aprender. (ENF3)

A equipe de enfermagem convive rotineiramente com a complexidade da hemodiálise, evidenciando-se assim, a importância de sua qualificação e do conhecimento que estes profissionais devem possuir para atuar no processo técnico do tratamento e diante de possíveis complicações ${ }^{9}$. Assim, agir com propriedade no cenário tecnológico envolve dos profissionais uma prática baseada em evidências no tratamento hemodialítico ${ }^{10}$.

A compreensão das complicações da hemodiálise e do seu funcionamento é indispensável para que a equipe de enfermagem realize uma assistência segura. Para tanto, é necessário manter o seu treinamento em cenários de prática que demandam cuidados intensivos 
aos pacientes que necessitam de intervenções rápidas e eficientes 11,12 .

É nesse contexto que o enfermeiro exerce um papel fundamental nas atividades educativas, consideradas essenciais ao trabalho gerencial, e que devem ter como referência 0 modo de organização da assistência ${ }^{13}$.

Este estudo demonstrou, por meio das falas dos participantes, que a forma como foram adquiridos os conhecimentos para o manuseio da máquina de hemodiálise podem conduzir a equipe a falhas na assistência, produção de vícios e técnicas inadequadas que são repassadas para outros profissionais e, consequentemente, comprometendo a segurança do paciente. Desta maneira, observa-se a necessidade de implementação de um serviço de educação permanente, no que concerne aos conhecimentos teóricos e práticos para o manejo do equipamento e de suas especificidades.

\section{A hemodiálise é coisa séria}

Nesta categoria apresenta-se os relatos da equipe de enfermagem no que concerne aos conhecimentos acerca da rotina de cuidados específicos realizados na pré-diálise.

Eu jamais vou ligar um paciente na máquina [hemodiálise] se eu observar que os sinais vitais, os parâmetros não estão cabíveis para ligar. As vezes o paciente está hipotenso ou hipertenso, assim não dá. Tem que avaliar os sinais vitais. (TE3)

[...] eu me sinto preparado apenas para ver o que é de minha competência, que é avaliar os sinais vitais antes da hemodiálise, testar o cateter posicionar o paciente no leito, conter se for preciso [...]. (TE4)

[...] a hemodiálise é um procedimento de muito risco, principalmente aqui na UTI onde os pacientes são instáveis. (TE7)

Então, para começar a gente tem que ter o cuidado com o cateter, é primordial. Antes de ligar o paciente devo avaliar os sinais vitais, se está hipertenso ou hipotenso e a hipoglicemia é muito comum. (ENF3)

Ao iniciar-se a hemodiálise, principalmente em pacientes de UTI, é indispensável que a equipe de enfermagem conheça e execute os cuidados iniciais que antecedem 0 procedimento. Dentre estes cuidados $^{14}$ estão, o monitoramento dos sinais vitais, avaliação da presença de dor, verificação da permeabilidade dos acessos para hemodiálise, monitorização da presença de sinais flogísticos e de medidas para controle de infecções ${ }^{14}$.

Ao enfermeiro compete também, orientação e supervisão dos procedimentos de desinfecção de equipamentos, avaliação dos exames complementares, registro no prontuário, provimento de material, verificação da dosagem de anticoagulante, acompanhamento da programação da ultrafiltração prescrita junto aos parâmetros da máquina, além de avaliação da necessidade de intervenção, de 
acordo com alterações dos

parâmetros hemodinâmicos ${ }^{15}$.

Assim, a assistência de enfermagem prestada aos pacientes durante o tratamento hemodialítico demanda uma gama de conhecimentos e nessa perspectiva, questionou-se a equipe sobre as principais complicações observadas durante a hemodiálise.

\begin{abstract}
Hipoglicemia, hipotensão, sudorese, câimbras, agitação, sonolência e quando o paciente para [PCR], já começamos a devolver (sangue do sistema para o paciente), e reanimar o paciente, mas infelizmente este paciente que parou comigo na hemodiálise foi a óbito (TE 4).
\end{abstract}

[...] as mais comuns são hipotensão, hipoglicemia, rebaixamento de nível de consciência deste cliente, um circuito que coagula e tem que tomar cuidado na hora de devolver. Se for o caso de uma fístula arteriovenosa tem que observar se o local da inserção não está edemaciado, porque se estiver fazendo edema deve-se parar a hemodiálise e puncionar novamente a fístula. Tem as taquicardias também (ENF 2).

[...] na UTI eu já vi muitas situações de hipoglicemia $e$ paciente parar [PCR] devido à hipotensão (TE 2).

Durante tratamento hemodialítico podem ocorrer diversas complicações, como a hipertensão, hipotensão, náuseas e vômitos, câimbras musculares, dor, arritmias cardíacas, infecções, dentre outras ${ }^{5,16,17}$. Alterações cardiológicas e, consequentemente, uma maior disposição à complicações também podem ser evidenciada, uma vez que as arritmias cardíacas são potencializadas pela circulação extracorpórea da terapia hemodialítica e pela remoção significativa de sangue do sistema vascular ${ }^{18}$.

É fundamental a observação contínua do paciente no decorrer da sessão de hemodiálise, com foco na prevenção, monitorização e intervenção nas complicações ${ }^{6}$. Nesse contexto, tem-se destacado a importância do conhecimento sobre a manipulação da máquina de hemodiálise e de habilidades técnicas específicas, para que se possa intervir de maneira correta diante das possíveis complicações, priorizando intervenções seguras e eficientes para o paciente ${ }^{19}$.

Para tanto, a atuação do(a) enfermeiro(a) não se resume a reversão de complicações, mas é necessário que se utilize de conhecimentos próprios da profissão, com 0 intuito de aperfeiçoar o processo de cuidar, de forma a garantir a resolutividade dos problemas de saúde, dentro daquilo que lhe compete 20,21. Logo, a educação permanente é uma estratégia fundamental para a composição de uma equipe de enfermagem qualificada e treinada ${ }^{6}$.

Neste estudo observou-se que a equipe de enfermagem não só tem se deparado com complicações intradialíticas no cenário da UTI, como as conseguem identificá-las devido à vivência profissional. Contudo, ainda carecem de embasamento teórico acerca da fisiopatologia e condutas que 
abarcam o contexto do procedimento dialítico (paciente e condições de adoecimento, complicações e execução das técnicas).

\section{0 conhecimento é para todos}

Nesta categoria, os relatos evidenciam a necessidade de educação continuada e educação permanente, pois na concepção da equipe de enfermagem, os conhecimentos em hemodiálise não devem ser restritos a um pequeno grupo.

Eu entendo que é necessário um processo de reciclagem contínua, um aperfeiçoamento do conhecimento na hemodiálise para quem manuseia, porque é coisa séria e pode levar o paciente à morte em uma complicação e você não sabe o que fazer [...]. (TE3)

A capacitação para todos é válida. Temos colegas que tem medo de fazer hemodiálise, apesar de já atuarem na UTI há um ou dois anos. Eles têm medo porque não tem segurança. (TE6)

[...] acho que todos os técnicos de enfermagem deveriam estar inseridos na rotina da hemodiálise, com capacitações. (ENF1)

Eu acho muito importante, uma coisa é a gente aprender por conta e outra é você ter o alicerce, $a$ base, o que é hemodiálise realmente, $o$ significado do porquê fazer, o que a máquina faz, a função do capilar, da hemofiltração e a limpeza. (ENF3)

Define-se

educação

permanente como uma proposta com intuito formativo que valoriza 0 saber e o fazer dos profissionais da saúde e de suas intervenções a partir das reflexões baseadas na aprendizagem, com a perspectiva de transformação de suas práticas ${ }^{22}$. Já, a educação continuada é um processo de atualização técnica científica e contínua que oferece ao profissional, a reflexão de suas práticas e promoção do desenvolvimento pessoal, considerando um conjunto de experiências subsequentes à formação inicial para atualização de seus conhecimentos ${ }^{23}$.

A partir da necessidade de conhecimento teórico e científico dos profissionais que atuam na UTI e diretamente com os pacientes em hemodiálise, entende-se a necessidade de uma proposta de educação permanente, pois ela é compreendida ${ }^{24}$ como uma política pedagógica que produz conhecimentos no cotidiano das instituições de saúde com a prática de ensino e aprendizagem, a partir da realidade do serviço e suas dificuldades.

Estudos enfatizam que a viabilização e continuidade do processo educativo da equipe de enfermagem estão atreladas as atividades gerenciais do(a) enfermeiro(a) e em sua capacidade de identificar as necessidades de aprendizagem dos profissionais, especialmente, aquelas oriundas do setor de atuação contribuem para a mudança de práticas, usualmente realizadas $22,25,26$.

Ademais, o conhecimento acerca das principais complicações e 
a identificação das intervenções de enfermagem durante o tratamento hemodialítico é fundamental para assistência de enfermagem de qualidade ${ }^{25}$.

\section{CONSIDERAÇÕES FINAIS}

Revelou-se que, embora a equipe de enfermagem não tenha participado de atividades educativas específicas para o manuseio da máquina de hemodiálise e assistência específica, a mesma consegue desenvolver os principais cuidados aos pacientes, por meio do conhecimento compartilhado entre colegas de trabalho que possuem maior experiência neste cenário.

Os principais conhecimentos da equipe relacionam-se a rotina dos cuidados específicos durante todo o processo hemodiálitico e também, os relacionados as complicações.

Assim, diante desses achados, pode-se afirmar que há necessidade de medidas educativas condizentes com o processo de ensino e aprendizagem da equipe de enfermagem atuante na UTI, no que concerne os conhecimentos e técnicas necessárias aos cuidados intensivos aos pacientes em tratamento hemodialítico.

Este estudo teve como limitações o quantitativo de participantes e por ter sido realizado somente em um único setor da instituição investigada. Contudo, entende-se que esta pesquisa traz valiosas contribuições às equipes de enfermagem que atuam no tratamento hemodialítico durante os cuidados intensivos.

\section{REFERÊNCIAS}

1. Massaroli R, Martini JG, Massaroli A, Lazzari DD, Oliveira SN, Canever BP. Trabalho de enfermagem em unidade de terapia intensiva e sua interface com a sistematização da assistência. Rev Esc Anna Nery. 2015; 19(2):252-8.

2. Silva PEBB, Mattos $M$ de. Complicações hemodialíticas na unidade de terapia intensiva. Rev enferm UFPE online. 2019; 13(1):162-168.

3. Rocha MTFB, Oliveira CM, Fecury AA, Dendacsk CV, Dias CAGM, Oliveira E. The role of nursing in the hemodialysis session. Multidiscip sci j. 2017; 2(4):39-52

4. Souza VJ. A importância dos cuidados de enfermagem prestada em terapia intensiva a pacientes em processos hemodialíticos venosos contínuos: pesquisa bibliográfica. Rev eletrônica atualiza saúde. 2015; 1(1):99-108.

5. Dallacosta FM, Dallacosta $\mathrm{H}$, Mitrus L. Detecção precoce de doença renal crônica em população de risco. Cogitare enferm. 2017; 22(2):e48714.

6. Morton PG, Fontaine DK. Cuidados críticos de enfermagem: uma 
abordagem holística. Rio de Janeiro: Guanabara Koogan; 2011.

7. Santana SS, Fontenelle T, Magalhães LM. Assistência de enfermagem prestada aos pacientes em tratamento hemodialítico nas unidades de nefrologia. Rev cient ITPAC. 2013; 6(3):1-11.

8. Bardin L. Análise de conteúdo. Edições 70: Lisboa; 2010.

9. Brasil. CNS. Resolução $n^{\circ}$ 466,2012. Diretrizes e Normas Regulamentadoras de pesquisa envolvendo seres humanos. Brasília, 13 jun. 2013. Seção 1 p.59. [acesso em 03 de dezembro de 2017] Disponível em: http: / /bvsms.saude.gov.br/bvs/sa udelegis/cns/2013/res0466_12_12 _2012.html

10. Louro TQ, Silva RCL, Moura LF, Machado DA. A terapia intensiva e as tecnologias como marca registrada. Rev pesqui cuid fundam. 2012; 4(3):2465-82.

11. Valim A. Prática assistencial de enfermagem nas emergências Interdialíticas na unidade de hemodiálise fundamentada em Wanda de Aguiar Horta. (Monografia) -Universidade do extremo sul catarinense - UNESC, Criciúma (SC); 2012. [acesso em 13 de agosto de 2017]. Disponível em:

http: //200.18.15.27/handle/1/10 90

12. Barbosa GS, Valadares GV. Tornando-se proficiente: o saber fazer do enfermeiro de hemodiálise. Rev Esc Anna Nery. 2014; 18(1):163-166.

13. Sanches POS, Tavares RP, Lago CCL. Assistência de enfermagem frente às principais complicações do tratamento hemodialítico em pacientes renais crônicos. Rev enferm contemp. 2013; 2(1):169183.

14. Lazzari DD, Schmidt N, Jung W. Educação continuada em unidade de terapia intensiva na percepção de enfermeiras. Rev enferm UFSM. 2012; 2(1):88-96.

15. Freitas RLS, Mendonça AEO. Cuidados de enfermagem ao paciente renal crônico em hemodiálise. Rev cult cient UNIFACEX. 2016; 14(2):22-35.

16. Oliveira NB, Costa e Silva FV, Assad LG. Competências do enfermeiro especialista em nefrologia. Rev Enferm UERJ. 2015; 23(3):375-80.

17. Pereira MRS, Bispo AO, Ramalho LP, Teixeira LSLP, Rodrigues JA. Papéis de enfermagem na hemodiálise. Rev bras educ saúde. 2013; 3(2):26-36.

18. Araújo ACS, Santo ES A importância das intervenções do enfermeiro nas intercorrências durante a sessão de hemodiálise. Rev cad saúde desenvolv. 2012; 1(1):44-58.

19. Cardoso BG, Carneiro TA, Magro MCS. Recuperação de pacientes com lesão renal aguda dialítica e 
não dialítica. Cogitare enferm. 2017; 22(1):1-9.

20. Silva FRC, Santos MS, Souza PV, Pereira RG, Silva FWT. Nursing and complication frequently during hemodialysis: literature review. ReonFacema. 2016; 2(2):207-11.

21. Noleto ISC, Modesto AP, Mota TC, Sousa MEC, Carvalho TAB, Cariman SLS, Leite HDCS. Complicações graves evitáveis pela equipe de enfermagem ao paciente em hemodiálise. Rev eletrônica acervo saúde. 2017; 9(3):1153-8.

22. Lavich CRP, Terra MG, Mello AL, Raddatz M, Arnemann CT. Ações de educação permanente dos enfermeiros facilitadores de um núcleo de educação em enfermagem. Rev gaúch enferm. 2017; 38(1):01-06

23. Peixoto LS, Gonçalves LC, Costa TD, Tavares CMM, Cavalcanti ACD, Cortez EA. Educação permanente, continuada e em serviço: desvendando seus conceitos. Enferm glob. 2013; (29):324-340.

24. Ceccim RB, Ferla AA. Dicionário da educação profissional em saúde. Fundação Oswaldo Cruz. Escola Politécnica de Saúde Joaquim Venâncio; 2009. [acesso em 17 de agosto de 2017]. Disponível

em: http:/ / www.epsjv.fiocruz.br/dic ionario/verbetes/edupersau.html

25. Peixoto LS, Pinto ACS, Izu $M$, Tavares CMM, Rosas AMMTF. Perception of nurses in relation to training services offered through the service of continuous. Rev Pesqui Cuid Fundam. 2015; 7(2):2323-35.

26. Nascimento VF, Silva RCR. Assistência de enfermagem ao recém-nascido pré-termo frente às possíveis intercorrências. Rev enferm UFSM. 2014; 4(2):429438.

Conflito de interesses: Os autores declaram não haver conflito de interesses.

Participação dos autores:

- Concepção: Silva PEBB, Mattos M.

- Desenvolvimento: Silva PEBB, Mattos M.

- Redação e revisão: Silva PEBB, Mattos M.

Como citar este artigo: Silva PEBB, Mattos M. Conhecimentos da equipe de enfermagem no cuidado intensivo a pacientes em hemodiálise. J Health NPEPS. 2019; 4(1):200-209. 